\title{
Prevalence and reasons of increased type 2 diabetes in Gulf Cooperation Council Countries
}

\author{
Mohammed Z. Aljulifi, SBFM, SADF.
}

\begin{abstract}
تهدف هذه الدراسة إلى مراجعة البيانات المنشورة حول انتشار مرض النشاف السكري

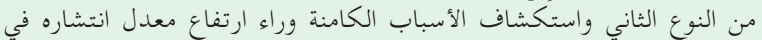

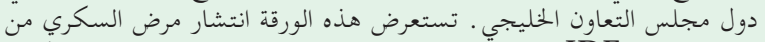

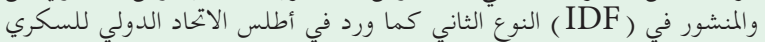

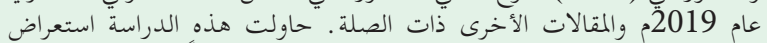

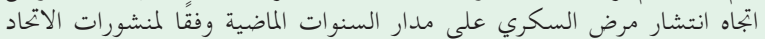

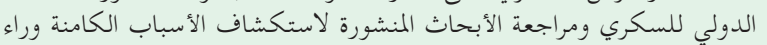

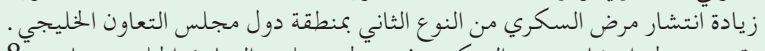

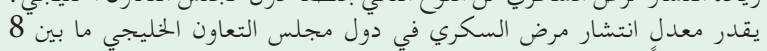

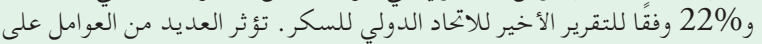

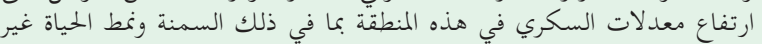

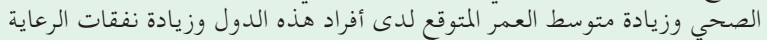

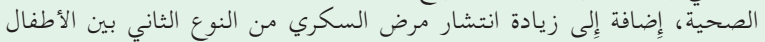

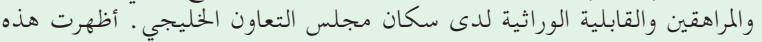

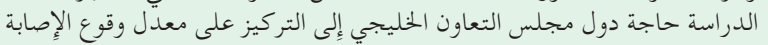

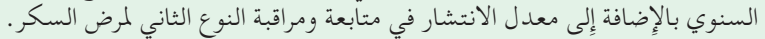

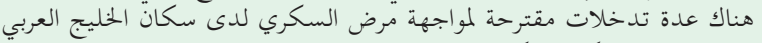

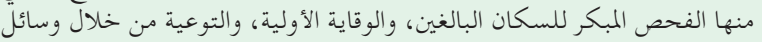

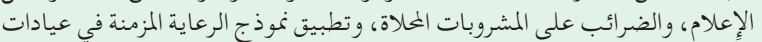

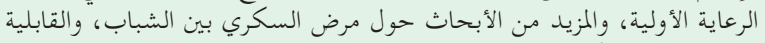

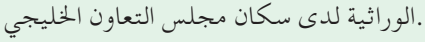

Arab Gulf Cooperation Council countries are considered as one of the most regions exhibiting a high prevalence of diabetes including the kingdom of Saudi Arabia, Bahrain, Qatar, Oman, Kuwait, and United Arab of Emirates, which have similar population characteristics (for example, religion, language, lifestyle, diet, and income). The frequency rate of diabetes in these countries ranged from 8 to $22 \%$ according to the last International Diabetes Federation (IDF) report. Many factors impact the prevalence in this region including obesity, unhealthy lifestyle, increased life expectancy, increased healthcare expenditures, increased the incidence of type 2 diabetic mellitus (T2DM) among children and young persons, and genetic susceptibility. This study aims to review the published papers on the incidence of T2DM and explore the most reasons behind elevated incidence of T2DM in these countries.

Keywords: diabetes mellitus type 2; incidence; prevalence; reasons; Gulf countries

Saudi Med J 2021; Vol. 42 (5): $481-490$ doi: 10.15537/smj.2021.42.5.20200676
From the Department of Family Medicine, College of Medicine, Majmaah University, Majmaah, Kingdom of Saudi Arabia.

Address correspondence and reprint request to: Dr. Mohammed Z. Aljulifi, Department of Family Medicine, College of Medicine, Majmaah University, Majmaah, Kingdom of Saudi Arabia. E-mail:_mzm428@gmail.com/m.aljulifi@mu.edu.sa ORCID ID: http://orcid.org0000-0002-1401-5305

A pproximately 415 million individuals worldwide are diabetic and this number is expected to be 642 million by $2040 .{ }^{1}$ As evidence from the current literature suggests that more implications and surveillance approaches should be introduced, data from diabetes figures showed a notable growing through the last 2 decades in Gulf Cooperation Council (GCC) countries. In the kingdom of Saudi Arabia, the prevalence rate of diabetes has been estimated to be $9 \%-22 \%$ from the years 1980 to 2008 as reports in 2016 show that the number of Saudi patients having diabetes is estimated to be 7 million patients while another 3 million ones are thought to be prediabetic. ${ }^{2,3}$ The same trends were also noticed in Kuwait as the prevalence rate for men and women was $19 \%$ in 1980 to be increased up to $22 \%$ in the current decade. ${ }^{3,4}$

Diabetes mellitus is considered a multifactorial disorder that can be generated secondary to the presence of a genetic predisposition that is triggered by environmental factors. ${ }^{5,6}$ The main triggers and contributing factors would always remain the ones related to the lifestyle of the patient as diet, physical activity, smoking, and infections affecting the pancreas. $^{7-11}$ Moreover, the socio-economic status of each region affects the patients' abilities to have access to proper management modalities. ${ }^{12}$ Although many investments have been made by the GCC officials to control the diseases and reduce the recently increasing prevalence rates, it would seem difficult to control due to the projected involvement of aging, population growth, and unhealthy life-styles in increasing such rates. ${ }^{13}$ Age and obesity are considered the most risk 
factors responsible for increasing the prevalence of type 2 diabetes mellitus (T2DM). In the GCC region, the incidence rate of obesity has been estimated to be up to $40 \%{ }^{7,14}$ In a previous systematic review it was investigated that the prevalence of overweight and obesity increased from $4.3 \%$ in 1980 to $34.9 \%$ in 2009 in the Gulf countries. ${ }^{14}$ Obesity is marked as the most common risk factor that contributes to the development of diabetes as it creates a state of insulin resistance by triggering metabolic syndrome. ${ }^{15}$ Besides, the presence of comorbidities as hypertension and other chronic conditions might also be a contributing factor. ${ }^{16}$ The author has reviewed studies in the literature to shed more light on the incidence of T2DM and discuss the most common risk factors developing T2DM in these countries.

The current study aims to narratively review previous studies to investigate the incidence rates of diabetes among the different GCC countries and the potential reasons behind the elevated incidence of T2DM based on the International Diabetes Federation (IDF) atlas 2019. The author tried to present the trends of diabetes prevalence over years as per IDF publications and analyzed the data of reasons for high prevalence supported by local and national studies in the GCC area.

Prevalence of type 2 diabetes mellitus in the GCC. Type 2 diabetes mellitus is an increasingly common disease with many associated complications. This disease has a strong connection with the lifestyle, habits, and income of patients and communities. ${ }^{17}$ From 2000 to 2019 , the estimated prevalence of T2DM has tripled from 151 to 463 million worldwide. ${ }^{18}$ The burden of this disease is high. It is estimated that in 2017, approximately USD 727 billion was spent on patients with T2DM aged from 20 to 79 years old and in 2030 this it might reach to USD 825 billion worldwide in $2030 .{ }^{18}$

According to the IDF, diabetes' rate in 2019 was $9.3 \%$ which might react $10.9 \%$ by 2045 globally. ${ }^{18}$ In the 6 GCC countries, diabetic rate increased ${ }^{19}$ in 2015 , among 149,600 deaths cases in these countries GCC, $73 \%$ of them were because of most non-communicable diseases (NCDs). Cancer, diabetes, respiratory, and cardiovascular diseases are the most non-communicable diseases. ${ }^{20}$ The WHO and Bahrain government worked

Disclosure. The author has no conflict of interests, and the work was not supported or funded by any drug company. together to publish a report on Bahrain's health profile in 2015 . They found that $77.9 \%$ of all deaths caused by NCDs, $12.7 \%$ of them were caused by diabetes mellitus. ${ }^{21}$

A previous study reported that the prevalence of T2DM in these countries ranged from $4.3 \%$ to $34.9 \% .^{22}$ Type 2 diabetes mellitus prevalence among females in Arab countries was assessed in another study between 2002 and 2018. Qatar was the highest with $10.8 \%$ of patients with T2DM being female. However, the estimated weighted prevalence in other countries is $8.0 \%$ in the UAE, $8.0 \%$ in Saudi Arabia, $8.0 \%$ in Oman, and $5.4 \%$ in Kuwait. ${ }^{23}$ The incidence rate of T2DM in 2000 was $23.7 \%$ and increased to $25.4 \%$ in 2009. ${ }^{24}$ Using epidemiological modeling, the prevalence rate of T2DM increased from $8.5 \%$ in 1992 to $39.5 \%$ in 2022 among Saudi population. The prevalence of diabetes would expected to reduce by $10 \%$ in 2022 if the obesity prevalence decreased. ${ }^{25}$ The incidence rate of T2DM in Oman ranged from $10.4 \%$ to $21.1 \%$ among population aged above 20 years and this percentage is expected to increase $174 \%$ by $2025 .^{26}$

One prognostic study was conducted on diabetes in Qatar. This study predicts diabetes prevalence by 2050 compared to 2012 data. This study estimates that $24 \%$ of adult Qataris are going to be diabetic compared to $16.7 \%$ in 2012. The peak of the prevalence was noted among 55-64 years old as 35\% of the patients with T2DM and decreased among the elderly ( $\geq 65$ years). ${ }^{27}$

According to the IDF 2019 report, Kuwait comes first in diabetes prevalence among the 6 GCC countries with $22 \%$ of its population between 20 and 79 years old. However, the highest number of death cases due to diabetes are reported in Saudi, compared to other GCC countries. ${ }^{18}$ Table 1 gives more details about the prevalence of T2DM and other measures in GCC countries. ${ }^{18}$ However, Figure 1 shows the prevalence of diabetes starting from the IDF's first publication until its 9 th edition. . $^{1828-34}$

In the human development index, the GCC countries are classified as very high. ${ }^{35}$ Only one study evaluated the association between diabetes' prevalence and human development index in the Arab countries. It found a strong correlation between high diabetes prevalence and high human development index $(\mathrm{R}=0.81){ }^{36}$

The next article explore most causes resulted in increasing the prevalence of T2DM in the GCC countries. Reasons for high prevalence of T2DM in GCC countries:

i) Overweight and obesity. Obesity prevalence has almost tripled worldwide since 1975 to $13 \%$ for adults ( $\geq 18$ years) in $2016 .{ }^{37}$ The burden of obesity-related 
Type 2 diabetes in Gulf region ... Aljulifi

Table 1 - Summary of diabetes prevalence and diabetes related deaths according to the International Diabetes Federation (IDF) 2019.

\begin{tabular}{|c|c|c|c|c|}
\hline Countries & $\begin{array}{l}\text { Adults with diabetes } \\
\text { (20-79 years) In } 1000 \mathrm{~S} \\
\text { (CI) }\end{array}$ & $\begin{array}{c}\text { Diabetes (20-79 years) } \\
\text { National prevalence }(\%) \\
(\mathrm{CI})\end{array}$ & $\begin{array}{l}\text { Diabetes age-adjusted } \\
\text { (20-79 years) comparative } \\
\text { prevalence }(\%)(\mathrm{CI})\end{array}$ & $\begin{array}{l}\text { Diabetes related deaths } \\
\text { (20-79 years) } \\
\text { (CI) }\end{array}$ \\
\hline Saudi Arabia & $4,275.2(2,580.2-4,774.4)$ & $18.3(11.1-20.5)$ & $15.8(10.3-17.7)$ & $15,038.7(10,548.6-16,321.7)$ \\
\hline Bahrain & $202.7(185.2-222.9)$ & $16.3(14.9-17.9)$ & $15.6(14.0-17.2)$ & $537.9(498.7-584.4)$ \\
\hline United Arab Emirates & $1,223.4(1,079.1-1,444.4)$ & $15.4(13.6-18.2)$ & $16.3(13.6-19.2)$ & $2,092.9(1,886.2-2,384.1)$ \\
\hline Oman & $291.8(232.6-526.1)$ & $8.0(6.3-14.3)$ & $10.1(7.9-16.6)$ & $964.9(776.9-1,493.5)$ \\
\hline Qatar & $347.0(318.5-381.4)$ & $15.5(14.2-17.0)$ & $15.6(14.0-17.2)$ & $644.4(601.5-697.9)$ \\
\hline Kuwait & $681.1(456.3-780.5)$ & $22.0(14.7-25.2)$ & $12.2(8.2-14.1)$ & $1,692.6(1,248.4-1,872.9)$ \\
\hline \multicolumn{5}{|c|}{ CI: confidence interval } \\
\hline
\end{tabular}

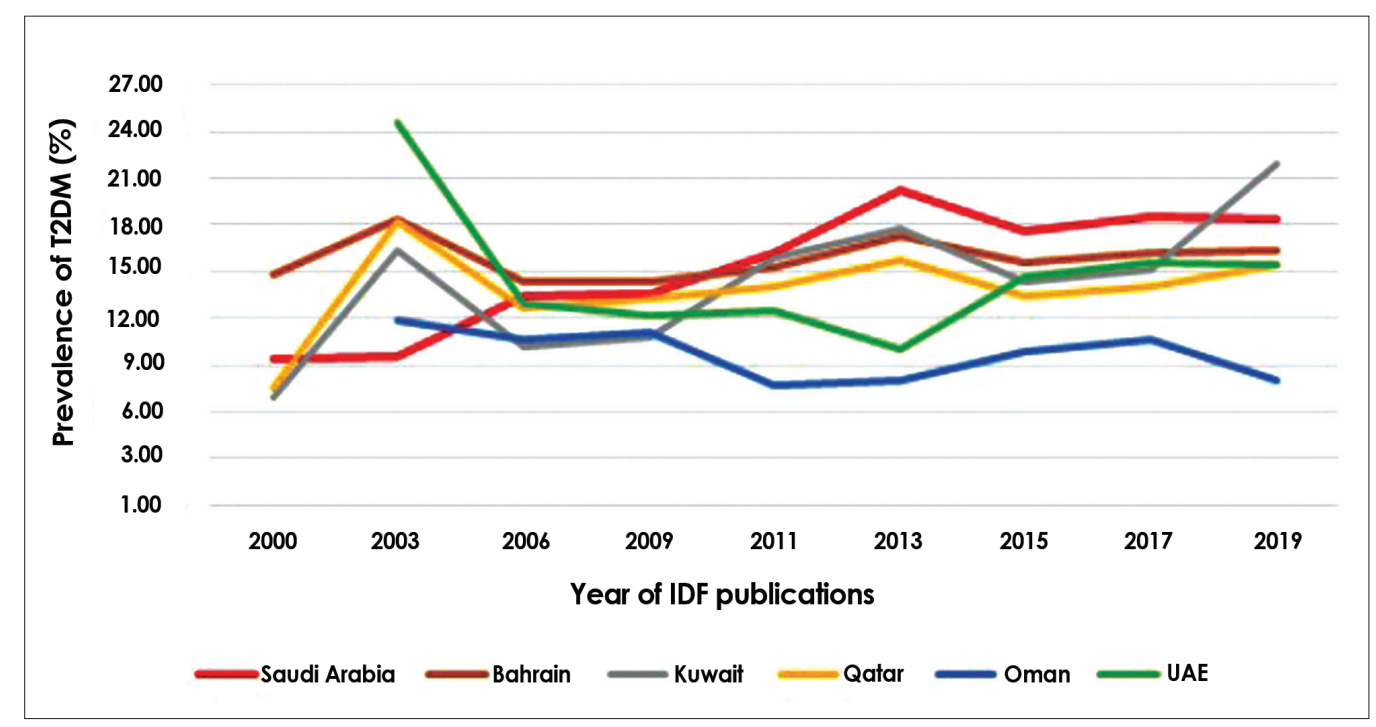

Figure 1 - Diabetes (20-79 years) national prevalence as per International Diabetes Federation (IDF) publication. T2DM: type 2 diabetic mellitus

Table 2 - Obesity prevalence in GCC area according to the world atlas.

\begin{tabular}{lcc}
\hline Countries & $\begin{array}{c}\text { Estimated } \\
\text { prevalence }\end{array}$ & $\begin{array}{c}\text { Worldwide } \\
\text { rank }\end{array}$ \\
\hline Kuwait & $37.9 \%$ & 11 \\
Saudi Arabia & $35.4 \%$ & 14 \\
Qatar & $35.1 \%$ & 15 \\
UAE & $31.7 \%$ & 20 \\
Bahrain & $29.8 \%$ & 25 \\
Oman & $27 \%$ & 29 \\
\hline
\end{tabular}

NCDs leads to approximately 36 million deaths each year. ${ }^{38}$ The data showed that being overweight and obese are the most common risk factors for T2DM. Approximately 25 to $50 \%$ of the adult population is overweight and 10 to $50 \%$ of the GCC population is obese. ${ }^{19}$ Kuwait is the first among the GCC countries in obesity prevalence as well as T2DM, while Oman has the lowest estimated prevalence with $27 \%$ of adults. Table 2 shows the prevalence of obesity in GCC countries according to the world atlas. ${ }^{39}$

It is estimated that $80 \%$ of Kuwaitis are obese. ${ }^{40}$ 
Forty-two to $44 \%$ of adult Kuwaiti women are obese. ${ }^{40-42}$ In Saudi Arabia, the prevalence of obesity among population aged 25 years and above is estimated to be $41 \%$ by 2022 in males and $78 \%$ in females. ${ }^{43}$

Many factors play a role in obesity in GCC countries. As the average age increases, the chance of being overweight and obese also increases. Physical activity, sedentary behavior, dietary behaviors, and sociodemographic factors such as low educational level, married, urban residence, and who did not work are highly associated with overweight/obesity among adults in the Gulf region. ${ }^{44}$

ii) Increased life expectancy. More than one-third of diabetes cases resulted from population growth and aging, (28\%) aging, and 32\% from both of them. ${ }^{34}$ The size of the general population in these GCC countries is expected to exceed 61.6 million by 2022 and the population' age and expanding size will likely exert huge pressure on the healthcare system. ${ }^{20}$

Increased life expectancy in the GCC is a reflection of improving health measures. Combating infectious disease, low rate of maternal and infant mortality, and the pan vaccination of all children has resulted in increased life expectancy. ${ }^{45}$ As shown in Table 3, there is a huge jump between life expectancy at birth in 1960 and 2017 in the GCC area. ${ }^{46}$ Gulf Cooperation Council countries provide free health services for all citizens. The number of hospitals in the GCC area increased from 622 hospitals in 2010 to 748 in 2016 . The number of physicians per 10,000 people has increased from 20.4 physicians in 2010 to 22.8 in 2014. Also, the nursing staff included over 287,000 nurses in 2016 compared to 200,500 in 2010 .

iii) Increased healthcare expenditures. According to the GCC Healthcare Sector Report (2015), the investment in healthcare infrastructure by GCC governments was significant in the last 25 years either medical cities or complexes. Healthcare expenditures in the GCC have increased on average from $2.95 \%$ in 2000 to $4.23 \%$ of the GDP in 2016 but, in general, is still below the $10 \%$ of GDP global average. Healthcare expenditures in these countries is expected to increase from USD 76.1 billion in 2017 to USD 104.6 billion in $2022 .{ }^{20}$

In the United States (2016) approximately $17 \%$ of the GDP was spent on healthcare while China spent around $4.98 \%{ }^{47}$ France and Germany spent more than $11 \%$ of their GDP on healthcare in $2016 .^{47}$

In contrast, Saudi Arabia is relatively higher than other GCC in total healthcare expenditures with 5.7\% of its GDP in 2016. Other GCC members spent the following percentages of their GDP on healthcare:
Table 3 - Life expectancy at birth and crude death rate in the gcc area.

\begin{tabular}{lcccc}
\hline Country & \multicolumn{2}{c}{ Life expectancy at birth } & \multicolumn{2}{c}{ Crude death rate } \\
& 1960 & 2017 & 1960 & 2017 \\
\hline Saudi Arabia & 45.638 & 74.874 & 20.319 & 3.446 \\
Bahrain & 51.869 & 77.032 & 14.694 & 2.368 \\
United Arab Emirates & 51.537 & 77.647 & 15.714 & 1.429 \\
Oman & 42.672 & 77.393 & 22.457 & 2.462 \\
Qatar & 61.094 & 79.981 & 9.398 & 1.169 \\
Kuwait & 59.343 & 75.311 & 9.544 & 2.601 \\
World & 52.58 & 72.283 & 17.714 & 7.542 \\
\hline
\end{tabular}

Bahrain (4.9\%), Oman (4.3\%), Kuwait (3.9\%), UAE (3.5\%), and Qatar (3.1\%). Between 2017 and 2022, the average growth rate of health expenditures in the GCC countries increased from $2.6 \%$ to $9.6 \% .^{20}$ Figure 2 gives more details about the progression in health expenditure between 2000 and 2016. ${ }^{47}$

Worldwide, the estimated annual health expenditure on diabetes is estimated to be USD760 billion and projected to approach USD825 billion by $2030 .{ }^{18}$ due to the increasing prevalence of T2DM and the costs per every diabetic patient with type 2, between 2012 and 2017, the economic costs of T2DM increased by $26 \%{ }^{48}$

Type 2 diabetes mellitus expenditures are still lower than expected in GCC countries. The North Africa and Middle East (MENA) region is expected to spend approximately USD24.7 billion on diabetes by $2030.3^{34}$ In the United States, $25 \%$ of health budget is spent on diabetes. Individuals with diabetes cost an average medical expenditure of approximately USD16,750 per year.

A previous study was conducted in Saudi Arabia and it was reported that the total annual medical cost for HbA1c <7 was USD1,384.19, while the cost for HbA1c 7-9\% increased to USD2,036.11, and for HbA1c $>9 \%$ the annual cost was USD3,104.86 with a significant difference of $p<0.001$. The high cost was related to diabetes-associated comorbidities. ${ }^{49}$ While, for diabetes, the annual cost for 20 million patients was USD4.53 billion (17 billion Saudi Riyals) in 2014. Most costs due to arising of diabetes' complications, the total cost would be USD11.45 billion for those with glucose intolerance, which represent approximately $17.5 \%$ of the Saudi Ministry of Health's budget. ${ }^{50}$

Table 4 summarizes the mean diabetes-related expenditure per person aged from 20 to 79 years with diabetes in GCC, ${ }^{18}$ which considered higher than in 


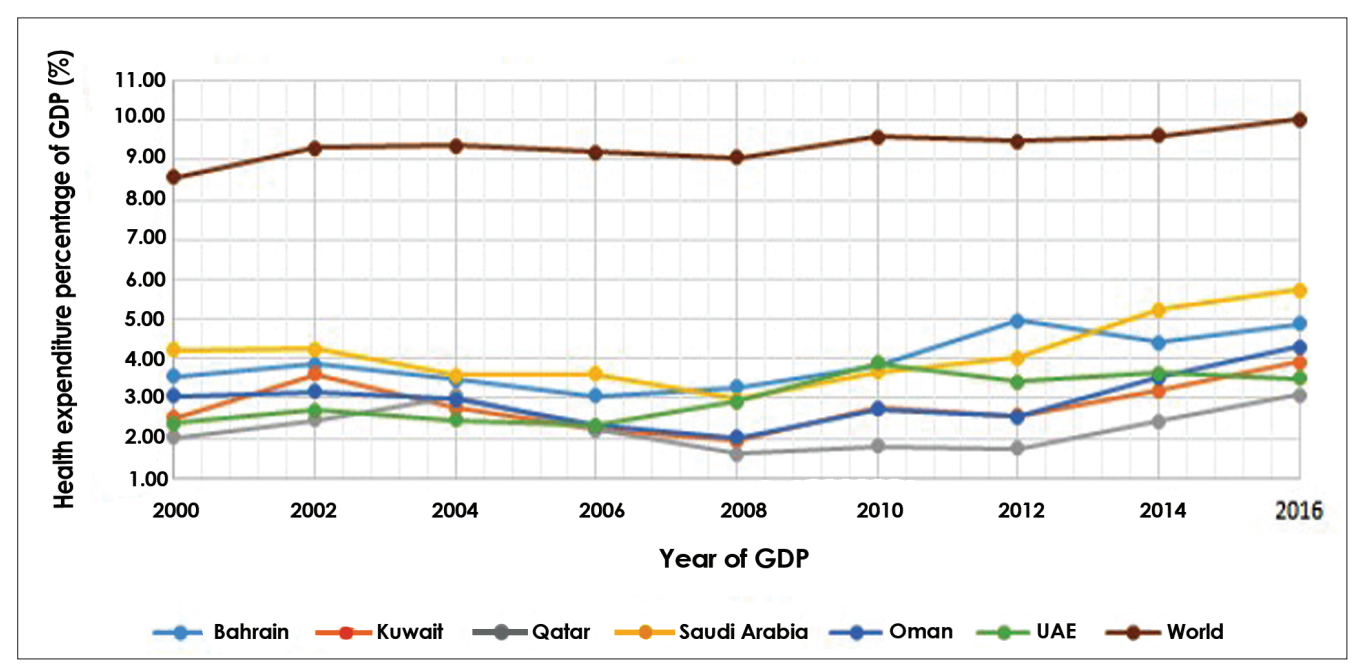

Figure 2 - Health expenditure of GDP (\%) between 2000 and 2016. The World Health Organization

Table 4 - Mean diabetes-related expenditure per person in Gulf Cooperation Countries (GCC), Mena, and worldwide according to the International Diabetes Federation (IDF) 2019.

\begin{tabular}{lcc}
\hline Country & $\begin{array}{c}\text { Mean diabetes- } \\
\text { related expenditure } \\
\text { (USD) per person } \\
\text { with diabetes } \\
\text { (20-79 years) }\end{array}$ & $\begin{array}{c}\text { Mean diabetes- } \\
\text { related } \\
\text { expenditure (ID) per } \\
\text { person with diabetes } \\
\text { (20-79 years) }\end{array}$ \\
\hline Saudi Arabia & $1,172.5$ & $3,186.3$ \\
Bahrain & $1,163.0$ & $1,974.6$ \\
United Arab Emirates & $1,237.3$ & $2,381.1$ \\
Oman & 752.6 & $3,283.2$ \\
Qatar & $1,751.2$ & $3,763.2$ \\
Kuwait & $1,089.6$ & $2,957.6$ \\
Mena & 475.3 & $1,469.6$ \\
World & $1,673.1$ & $2,480.5$ \\
\hline \multicolumn{3}{c}{} \\
\hline
\end{tabular}

that in MENA region, according to the IDF 2019 report. Bahrain is the lowest among the GCC countries and less than the global average. However, Qatar is the highest with international dollar $\$ 3,763.2$ in mean diabetes-related expenditures per person with diabetes. ${ }^{18}$ Type 2 diabetes mellitus-associated health expenditures in Qatar might increase by 200 to $600 \%$ accounting for $32 \%$ of total health expenditures by $2050 .{ }^{27}$

iv) Physical inactivity. Among the GCC population the rate of physical activity is lower than in many developed countries. ${ }^{51}$ It was showed that despite a low number of studies and lack of high-quality research, about 36.2 to $86 \%$ of men and 35 to $65.7 \%$ of women practice physical activity. However, a Saudi Study published in 2007 showed that only $6.1 \%$ of men and $1.9 \%$ of women are physically active. ${ }^{52}$ In addition, physical activity is low among adolescent populations, particularly females. ${ }^{53}$

In Kuwait, 57.9 to $72 \%$ of adult Kuwaitis are physically inactive, ${ }^{40,42,54}$ while $20 \%$ of adult Omanis sit for prolonged periods ( $\geq 7$ hours). Twenty-two percent of them are male and $26.9 \%$ are female. ${ }^{55}$

Balhareth et $\mathrm{al}^{44}$ concluded that elderly persons and women are less physically active, due to some cultural sensitivities that prevent women to practice exercise. Also, sandstorms, hot weather, passive transport opportunities, and urbanized environment are considered other barriers decreasing the physical activity.

v) Unhealthy diet. As economic growth increases so does the food per capita. Four out of 6 GCC countries were assessed by the Food and Agriculture Organization. ${ }^{56}$ Gulf Cooperation Council countries consumed a higher dietary energy, compared with the average world daily per capita caloric supply. The energy consumption progressively increased and exceeded 3,000 Kcal/person/day for in these GCC countries. ${ }^{56}$

A study was conducted in Qatar and showed that Qatari households ( $\mathrm{HHs}$ ) purchased more food versus non-Qataris HHs (2,118 g/capita/day versus $1,373 \mathrm{~g} /$ capita/day). ${ }^{57}$

A previous survey was conducted in 4 private schools, Sharjah, Emirate and it was found that 34\% of the students had a healthy behaviors in their eating and $19 \%$ ate fast food frequently or daily. ${ }^{58}$ 
In Kuwait, 83.8\% reported consumed low fruit and vegetables per day, thus being at higher risk for NCDs in general. The proportion was higher for women than men (86\% versus $81.4 \%)$. Consumption of both fruit and vegetables was less frequent in younger age groups. ${ }^{42}$

Urbanization and shifting from a traditional diet to westernized diet have been observed in the eastern Mediterranean region. Regarding urbanization diet, sugar, white bread, and excess fat are highly consumed, while grains, oils, vegetables, and legumes had a low consumption, which resulted in decreasing the availability of fruit by $7.8 \%$ and vegetables by $0.3 \%$ in these regions. ${ }^{59}$

vi) Increased prevalence of T2DM among children and adolescents. A significant increase in the incidence of T2DM was reported among children and adolescents. Type 2 diabetes mellitus represents almost $12 \%$ of all diabetes cases in children and adolescents. ${ }^{60}$ There was an increase of 35\% in T2DM prevalence between 2001 to 2009 in the United States. ${ }^{61}$

In Saudi Arabia, the overall prevalence of T2DM from 2006 to 2010 was 9\% among obese and overweight children. ${ }^{62}$ In a previous retrospective study, 11 patients are with T2DM out of 96 young diabetic patients in UAE. Of those patients, $9(82 \%)$ patients were obese, with BMIs above the 85 th percentile. $^{63}$

Another study was carried out in Kuwait to assess the incidence rate of T2DM among patients randomly selected from 182 schools. Those children were between 6 and 18 years old. Almost 45 child had T2DM and the prevalence among males was $47.3,95 \%$, while it was $26.3,95 \%$ among females with a highly significant different $(p=0.026) .{ }^{64}$

Before 2008 in Qatar, there were no registered cases of T2DM among children or adolescents. Since, the prevalence of T1DM increased from $1.82 / 100,000$ to 2.7/100,000 between 2012 and $2016 .{ }^{65}$

Increasing the rate of obesity and unhealthy lifestyles among children and adolescents in the GCC increased the risk of diabetes prevalence in those groups. More studies are needed to explore the magnitude of this problem in the GCC area.

vii) Genetic susceptibility. Genetics had a pivotal role in developing of T2DM. ${ }^{66}$ As a race, Arab is considered an independent risk factor for the development of diabetes. ${ }^{67} \mathrm{~A}$ study compared the prevalence of T2DM among Iraqi immigrants to native Swedes and found that T2DM was double among Iraqis compared with Swedes. ${ }^{68}$

One of the ways to assess gene-related diseases or phenotypes in a specific population is by analyzing single nucleotide polymorphism (SNP) alleles to identify loci that are associated with that disease or phenotype. There are several studies conducted in the GCC using SNP genotyping. One study examined the diabetes etiology among Saudi population by genotyping SNPs and assessed other associated risk factors. Consanguinity could promote the diabetes risk by onset of the disease and through strengthening the most possible genetic impacts on fasting blood glucose levels. ${ }^{69}$ In Saudi Arabia, there was a weak or no association of T2DM with the 2-transcription factor (TCF7L2) variants or P12A peroxisome proliferator' polymorphism-activated receptor gene (PPAR- $\gamma 2) .^{70,71}$ However, another casecontrolled study found a positive association between the $\mathrm{E} 23 \mathrm{~K}$ variant and T2DM in a Saudi population with an OR of 1.7 ( $p=0.0001) .{ }^{72}$ A systematic review of genetic markers of T2DM in Saudis recognized 23 polymorphisms in 17 genes which are highly correlated with increasing the risk of T2DM in people of Saudi ethnicity. One of the limitations of this study is its small sample size compared to European studies. ${ }^{73}$ Obesity and T2DM are known to be connected. So, one Saudi study tried to investigate the relation between obesity phenotypes and variants of 36 T2DM SNPs among Saudi population. ${ }^{74}$

In the UAE, data suggest that TCF7L2 and melanocortin 4 receptor (MC4R) increasing DM risks are correlated with variants, ${ }^{75,76}$ the same findings were found in Qatar. ${ }^{77}$ However, a study in Bahrain provided evidence of the potential involvement of T2DM risk factors adiponectin, $\mathrm{C} 1 \mathrm{Q}$, and collagen domaincontaining (ADIPOQ), independent of insulin and obesity resistance. ${ }^{78}$ While in Kuwait, the ACE I allele is associated with T2DM. ${ }^{79}$

In conclusion, some genetic variants might be associated with T2DM, but these data are inconsistent among GCC people. More local and regional studies are warranted to determine which gene variants are related to T2DM in this area.

Discussion. In addition to the previously mentioned points in this review, there are additional ones to be fully discussed in this literature. The variance in the prevalence rates among the reported countries can be noticed in this review. Therefore, it might not be right to apply the same interventional protocols to the same countries. Each country should apply its approaches based on the nature and demographics of its affected population and the prevalence of the aforementioned risk factors among them. As diabetes is a complex disorder with trending prevalence rates, the burden of the disease over the affected patients' life expectancies and healthcare, 
and the economic status of each country is also increasing. Therefore, strong efforts by the patients and governments should be applied for proper prevention and control of the disease. For an early and proper intervention of diabetes, healthy life-style protocols as a healthy diet and more physical activities should reduce the incidence of sedentary life and obesity and reduce the risk for having diabetes. ${ }^{80}$ There is a piece of strong evidence that these measures are very effective in the prevention and management of diabetes for prolonged time. ${ }^{80-83}$ In addition to being efficacious, such measures are also deemed suitable for every patient and can be applied at all socioeconomic levels. Mass education should also be approached to encourage individuals about the benefits of a healthy lifestyle and warn against the consequences and complications that may result from obesity and sedentary life. ${ }^{53}$ Other approaches by governments include making ways for easy access to the required healthcare resources and imposing taxes on the huge consumption of unhealthy food. In a study by Veerman et $a{ }^{8},{ }^{84}$ the authors estimated that an annual reduction of 800 diabetes cases could be achieved by raising the taxes on sugar rates by $20 \%$.

Another factor is the prevalence of diabetes per age group as more attention should be given to older patients as the prevalence rates seem to get higher as patients grow older which can be noticed in countries with higher life expectancies. The American Diabetes Association (ADA) previously showed that diabetes' mass screening should conduct by each country by the age of 45 years old by every country. ${ }^{85}$ A previously published survey-based investigation that the estimated prevalence rates and the associated factors in the GCC countries showed that the age increased the incidence rate of diabetes, particularly among those aged 60 years or older. ${ }^{13}$ However, this was not noticed with the population of Oman where the highest prevalence rate was noticed with the 50-59 age group which may be attributable to the differences in other factors as BMI, nutritional habits, and patients' education between the included countries. ${ }^{13}$ On contrast, a UAE study by Sulaiman et $\mathrm{a}^{86}$ showed that diabetes was significantly highly prevalent in patients $\geq 35$ years old. Consequently, further research and mass-screening projects are needed for more accurate estimations.

For long-term management of diabetes, the ADA also suggested that a chronic care model protocol should be applied in the primary care centers. ${ }^{87}$ To assess the integrity and efficacy of this model, Wan et $\mathrm{al}^{88}$ conducted a 5 -year cohort study investigating this approach in the management of 53,436 diabetic patients.
The authors reported that reduced complications and overall mortality rates were significantly noticed in their population by the end of the study follow-up period, in addition to the significant reductions in healthcare resources.

Gestational diabetes mellitus (GDM) might be a predisposing factor as previous studies showed. ${ }^{89,90} \mathrm{~A}$ previous study carried out in Saudi Arabia ${ }^{91}$ showed that the incidence rate of GDM in their population was $12.8 \%$ and therefore, frequent monitoring and adequate management approaches should be conducted for pregnant women. This rate is similar to a study that was conducted in Kuwait by Groof et al ${ }^{92}$ as the authors reported that the prevalence of GDM was $12.6 \%$ in pregnant women who had no previous history of diabetes, while women with polycystic ovary syndrome (PCOS) showed a higher developing diabetes risk. ${ }^{93}$ In a Qatari study, the authors reported that among the patients that were diagnosed with PCOS, $19.4 \%$ of them had prediabetes and another 9.7\% were diabetic. ${ }^{94}$ Asthma, hypertension, chronic lung diseases, cardiovascular diseases, and arthritis might also contribute to the risk of having diabetes later on as illustrated by Morgan et $\mathrm{al}^{13}$ and other studies. ${ }^{95,96}$ The authors also showed that increased urbanization in some countries (Oman and Saudi Arabia) might also be contributing factors that increased the prevalence of type 2 diabetes. However, the analysis from the same study showed that the prevalence of diabetes among the rural population $(10.5 \%)$ in the UAE was higher than the urban one $(7.2 \%)$. These rates might be subjected to selection biases as the study was based on questionnaires for the targeted populations and therefore, future studies with better sampling and adequate population are needed. Alhyas et $\mathrm{al}^{7}$ conducted a systematic review and showed that almost all of the included studies indicated that the frequency rate of diabetes was significantly higher in the urban than the rural population. This may be attributable to the stressful lifestyle and unhealthy dietary contents.

In conclusion, the prevalence of diabetes in the GCC countries is significantly high. Although many approaches have been made to reduce these high rates, no unified protocol has been sought which may be because the epidemiology of the disease is different by country. The author has discussed the relevant risk factors developing the disease. Furthermore, we would like to stress more on factors like urbanization, PCOS, and GDM because few investigations were published in this region. The prevention of diabetes is multifactorial and would require the integration of many approaches involving individuals as healthy diet intake and regular 
exercising, and governments as mass screening for patients at risk and education.

Acknowledgment. I would like to thank all the persons who provided the data for this study and I would like to thank the American Manuscript Editor for the effective revision and useful suggestion. Also, I would like to thank the Deanship of Scientific Research at Majmaah University for supporting this work under Project Number No. R-2021-65

\section{References}

1. Ogurtsova K, da Rocha Fernandes JD, Huang Y, Linnenkamp U, Guariguata L, Cho NH, et al. IDF Diabetes Atlas: Global estimates for the prevalence of diabetes for 2015 and 2040. Diabetes Res Clin Pract 2017; 128: 40-50.

2. Al Dawish MA, Robert AA, Braham R, Al Hayek AA, Al Saeed A, Ahmed RA, et al. Diabetes mellitus in Saudi Arabia: A review of the recent literature. Curr Diabetes Rev 2016; 12: 359-368.

3. Zabetian A, Kelli HM, Echouffo-Tcheugui JB, Narayan KM, Ali MK. Diabetes in the Middle East and North Africa. Diabetes Res Clin Pract 2013; 101: 106-122.

4. Alkandari A, Alarouj M, Elkum N, Sharma P, Devarajan S, Abu-Farha M, et al. Adult diabetes and prediabetes prevalence in Kuwait: Data from the Cross-Sectional Kuwait Diabetes Epidemiology Program. J Clin Med 2020; 9: 3420.

5. Hu FB. Sedentary lifestyle and risk of obesity and type 2 diabetes. Lipids 2003; 38: 103-108.

6. Hirschhorn JN. Genetic epidemiology of type 1 diabetes. Pediatr Diabetes 2003; 4: 87-100.

7. Alhyas L, McKay A, Majeed A. Prevalence of Type 2 Diabetes in the States of The Co-Operation Council for the Arab States of the Gulf: A Systematic Review. PLoS One 2012; 7: e40948.

8. Knip M, Veijola R, Virtanen SM, Hyöty H, Vaarala O, Akerblom HK. Environmental triggers and determinants of type 1 diabetes. Diabetes 2005; 54 Suppl 2: S125-S136.

9. Jeon CY, Lokken RP, Hu FB, van Dam RM. Physical activity of moderate intensity and risk of type 2 diabetes: a systematic review. Diabetes Care 2007; 30: 744-752.

10. Willi C, Bodenmann P, Ghali WA, Faris PD, Cornuz J. Active smoking and the risk of type 2 diabetes: a systematic review and meta-analysis. JAMA 2007; 298: 2654-2664.

11. Montonen J, Knekt P, Järvinen R, Aromaa A, Reunanen A. Whole-grain and fiber intake and the incidence of type 2 diabetes. Am J Clin Nutr 2003; 77: 622-629.

12. Standards of Medical Care in Diabetes. Diabetes Care 2004; 27 (Suppl 1): s15-s35.

13. Morgan SA, Ali MM, Channon AA, Al-Sabahi S, Al Suwaidi $\mathrm{H}$, Osman N, et al. Prevalence and correlates of diabetes and its comorbidities in four Gulf Cooperation Council countries: evidence from the World Health Survey Plus. I Epidemiol Community Health 2019; 73: 630-636.

14. Alhyas L, McKay A, Balasanthiran A, Majeed A. Prevalences of overweight, obesity, hyperglycaemia, hypertension and dyslipidaemia in the Gulf: systematic review. JRSM Short Rep 2011; 2: 55.

15. Després JP, Lemieux I. Abdominal obesity and metabolic syndrome. Nature 2006; 444: 881-887.

16. Gazzaz ZJ, Iftikhar R, Jameel T, Baig M, Murad MA. Association of dyslipidemia and comorbidities with risk factors among diabetic patients: A retrospective analysis. Diabetes Metab Syndr Obes 2020; 13: 935-941.
17. Collaborators GRF. Global, regional, and national comparative risk assessment of 79 behavioural, environmental and occupational, and metabolic risks or clusters of risks, 1990-2015: a systematic analysis for the Global Burden of Disease Study 2015. Lancet 2016; 388: 1659-1724.

18. International Diabetes Federation. IDF Diabetes Atlas,. 9th ed Brussels, Belgium: International Diabetes Fedration; 2019.

19. Al-Rubeaan K. The impact of diabetes mellitus on health and economy of Gulf Cooperation Council countries. Diabetes Manage 2014; 4: 381-390.

20. Alpen Capita Co. GCC health care industry. March 26, 2018. Available from: http://www.alpencapital.com/downloads/ reports/2018/GCC-Healthcare-Industry-Report-March-2018. pdf

21. World Health Organization. Bahrain health profile 2015. Geneva (SW): World Health Organization, Regional Office for the Eastern Mediterranean; 2017.

22. Alhyas L, McKay A, Majeed A. Prevalence of type 2 diabetes in the States of the cooperation council for the Arab States of the Gulf: a systematic review. PLoS One 2012; 7: e40948.

23. Al-Rifai R, Majeed M, Qambar M, Ibrahim A, AlYammahi K, Aziz F. Type 2 diabetes and pre-diabetes mellitus: a systematic review and meta-analysis of prevalence studies in women of childbearing age in the Middle East and North Africa, 2000-2018. Syst Rev 2019; 8: 268.

24. Alotaibi A, Perry L, Gholizadeh L, Al-Ganmi A. Incidence and prevalence rates of diabetes mellitus in Saudi Arabia: An overview. J Epidemiol Glob Health 2017; 7: 211-218.

25. Al Quwaidhi A. Epidemiological modelling of type 2 diabetes in Saudi Arabia: predicted trends and public health implications. Tyne (UK): Newcastle University; 2013.

26. Al-Lawati JA, Panduranga P, Al-Shaikh HA, Morsi M, Mohsin N, Khandekar RB, et al. Epidemiology of Diabetes Mellitus in Oman: Results from two decades of research. Sultan Qaboos University Medical Journal 2015; 15: e226-e233.

27. Awad SF, O'Flaherty M, Critchley J, Abu-Raddad LJ. Forecasting the burden of type 2 diabetes mellitus in Qatar to 2050: A novel modeling approach. Diabetes Res Clin Pract 2018; 137: 100-108.

28. International Diabetes Federation. Diabetes Atlas 2000. [cited 2020]. Available from: https://idf.org/e-library/epidemiologyresearch/diabetes-atlas.html

29. Gan D. Diabetes atlas. Brussels (BL): International Diabetes Federation; 2003.

30. Mbyana J, Gan D, Allgot B, Bakker K, Brown J, Ramachandran A. Diabetes Atlas. Brussels: International Diabetes Federation; 2006.

31. Unwin N, Whiting D, Gan D, Jacqmain O, Ghyoot G. Diabetes Atlas. Brussels: International Diabetes Federation; 2009.

32. Aguiree F, Brown A, Cho N, Dahlquist G, Dodd S, Dunning $\mathrm{T}$, et al. Diabetes Atlas. Brussels: International Diabetes Federation; 2013.

33. International Diabetes Federation. Diabetes Atlas, 7th ed. Brussels: International Diabetes Federation; 2015.

34. International Diabetes Federation. Electronic resource. Brussels: International Diabetes Federation; 2017.

35. United Nations Development Programme. Human development index. [cited 2019]. Available from: http://hdr. undp.org/sites/default/files/hdr2019.pdf

36. Boutayeb A, Lamlili M, Boutayeb W, Maamri A, Ziyyat A, Ramdani N. The rise of diabetes prevalence in the Arab region. Open Journal of Epidemiology 2012; 2: 55-60. 
37. World Health Organization. Obesity and overweight. [cited 2020 March 3]. Available from: https://www.who.int/ news-room/fact-sheets/obesity-and-overweight

38. Banjare J, Bhalerao S. Obesity associated noncommunicable disease burden. International Journal of Health \& Allied Sciences 2016; 5: 81.

39. Dillinger J. The most obese countries in the world. [cited 2018 February 16]. Available from: https://www.worldatlas.com/ articles/29-most-obese-countries-in-the-world.html.

40. Weiderpass E, Botteri E, Longenecker JC, Alkandari A, Al-Wotayan R, Al Duwairi Q, et al. The prevalence of overweight and obesity in an adult Kuwaiti population in 2014. Front Endocrinol (Lausanne) 2019; 10: 449.

41. al-Awadi F, Amine EK. Overweight and obesity in Kuwait. $J R$ Soc Health 1989; 109: 175-177.

42. Al-Duwairi Q. Eastern Mediterranean Approach for Control of Non Communicable Diseases: Ministry of Health in the State of Kuwait [cited 2015]. Available from: https://www.who.int/ ncds/surveillance/steps/Kuwait_2014_STEPS_Report.pdf.

43. Al-Quwaidhi AJ, Pearce MS, Critchley JA, Sobngwi E, O'Flaherty M. Trends and future projections of the prevalence of adult obesity in Saudi Arabia, 1992-2022. East Mediterr Health J 2014; 20: 589-595.

44. Balhareth A, Meertens R, Kremers S, Sleddens E. Overweight and obesity among adults in the Gulf States: A systematic literature review of correlates of weight, weight-related behaviours, and interventions. Obesity Reviews 2019; 20: 763-793.

45. Mamtani R, Lowenfels A. Critical Issues in Healthcare Policy and Politics in the Gulf Cooperation Council States: Georgetown University Press; 2018.

46. The World Bank. Data Bank, World Development Indicators 2019. [cited 2019]. Available from: https://databank. worldbank.org/home.aspx

47. World Health Organization. Global Health Expenditure Database [cited 2020]. Available from: https://apps.who.int/ nha/database.

48. American Diabetes Association. Economic costs of diabetes in the U.S. in 2017. Diabetes Care 2018; 41: 917-928.

49. Almutairi N, Alkharfy KM. Direct medical cost and glycemic control in type 2 diabetic Saudi patients. Appl Health Econ Health Policy 2013; 11: 671-675.

50. Mokdad A, Tuffaha M, Hanlon M, El Bcheraoui C, Daoud F, Al Saeedi M, et al. Cost of diabetes in the Kingdom of Saudi Arabia, 2014. J Diabetes Metab 2015; 6: 2.

51. Mabry R, Reeves M, Eakin E, Owen N. Evidence of physical activity participation among men and women in the countries of the Gulf Cooperation Council: a review. Obes Rev 2010; 11 : 457-464.

52. Al-Nozha M, Al-Hazzaa H, Arafah M, Al-Khadra A, Al-Mazrou YY, Al-Maatouq M, et al. Prevalence of physical activity and inactivity among Saudis aged 30-70 years. Saudi Med J 2007; 28: 559-568.

53. Mabry R, Koohsari MJ, Bull F, Owen N. A systematic review of physical activity and sedentary behaviour research in the oil-producing countries of the Arabian Peninsula. BMC Public Health 2016; 16: 1003.

54. Alarouj M, Bennakhi A, Alnesef Y, Sharifi M, Elkum N. Diabetes and associated cardiovascular risk factors in the State of Kuwait: the first national survey. Int J Clin Pract 2013; 67: 89-96.
55. Mabry RM, Morsi M, Owen N. Descriptive epidemiology of sitting time in omani men and women: A known risk factor for non-communicable diseases. Oman Med J 2017; 32: 233-239.

56. Roser M, Ritchie H. Food per Person. [cited 2019]. Available from: https://ourworldindata.org/food-per-person.

57. Al-Thani M, Al-Thani AA, Al-Mahdi N, Al-Kareem H, Barakat $\mathrm{D}$, Al-Chetachi W, et al. An overview of food patterns and diet quality in Qatar: Findings from the National Household Income Expenditure Survey. Cureus 2017; 9: e1249.

58. Al-Yateem N, Rossiter R. Nutritional knowledge and habits of adolescents aged 9 to 13 years in Sharjah, United Arab Emirates: a cross-sectional study. East Mediterr Health J 2017; 23: 551-558.

59. Musaiger AO, Al-Hazzaa HM. Prevalence and risk factors associated with nutrition-related noncommunicable diseases in the Eastern Mediterranean region. Int J Gen Med 2012; 5: 199-217.

60. Chiang JL, Maahs DM, Garvey KC, Hood KK, Laffel LM, Weinzimer SA, et al. Type 1 diabetes in children and adolescents: A position statement by the American Diabetes Association. Diabetes Care 2018; 41: 2026-2044.

61. Dabelea D, Mayer-Davis EJ, Saydah S, Imperatore G, Linder B, Divers J, et al. Prevalence of type 1 and type 2 diabetes among children and adolescents from 2001 to 2009. JAMA 2014; 311: 1778-17786.

62. Al-Agha A, Ocheltree A, Shata N. Prevalence of hyperinsulinism, type 2 diabetes mellitus and metabolic syndrome among Saudi overweight and obese pediatric patients. Minerva Pediatr 2012; 64: 623-631.

63. Punnose J, Agarwal M, Bin Uthman S. Type 2 diabetes mellitus among children and adolescents in Al-Ain: a case series. The Eastern Mediterranean Health Journal 2005; 11: 788-797.

64. Moussa M, Alsaeid M, Abdella N, Refai T, Al-Sheikh N, Gomez J. Prevalence of type 2 diabetes mellitus among Kuwaiti children and adolescents. Med Princ Pract 2008; 17: 270-275.

65. Alyafei F, Soliman A, Alkhalaf F, Sabt A, De Sanctis V, Waseef $\mathrm{R}$, et al. Incidence of type 1 and type 2 diabetes, between 2012-2016, among children and adolescents in Qatar. Acta Biomed 2018; 89 (Suppl 5): 7.

66. Ahlqvist E, Ahluwalia TS, Groop L. Genetics of type 2 diabetes. Clin Chem 2011; 57: 241-254.

67. Sherif S, Sumpio BE. Economic development and diabetes prevalence in MENA countries: Egypt and Saudi Arabia comparison. World J Diabetes 2015; 6: 304-311.

68. Bennet L, Groop L, Lindblad U, Agardh C, Franks P. Ethnicity is an independent risk indicator when estimating diabetes risk with FINDRISC scores: a cross sectional study comparing immigrants from the Middle East and native Swedes. Prim Care Diabetes 2014; 8: 231-238.

69. Gosadi IM, Goyder EC, Teare MD. Investigating the potential effect of consanguinity on type 2 diabetes susceptibility in a Saudi population. Hum Hered 2014; 77: 197-206.

70. Alsmadi O, Al-Rubeaan K, Mohamed G, Alkayal F, Al-Saud H, Al-Saud NA, et al. Weak or no association of TCF7L2 variants with Type 2 diabetes risk in an Arab population. BMC Med Genet 2008; 9: 72.

71. Wakil SM, Al-Rubeaan K, Alsmadi O, Imtiaz F, Carroll P, Rajab $\mathrm{M}$, et al. The peroxisome proliferator-activated receptor- 2 P12A polymorphism and type 2 diabetes in an Arab Population. Diabetes Care 2005; 29: 171-172. 
72. Alsmadi O, Al-Rubeaan K, Wakil SM, Imtiaz F, Mohamed G, Al-Saud H, et al. Genetic study of Saudi diabetes (GSSD): significant association of the KCNJ11 E23K polymorphism with type 2 diabetes. Diabetes Metab Res Rev 2008; 24: 137-140.

73. Siddiqui K, Musambil M, Usmani AM. Established type 2 diabetes-susceptibility genetic variants in Saudi ethnicity: a mini-systematic review. Journal of Biochemical and Clinical Genetics 2018; 1: 57-65.

74. Al-Daghri NM, Alkharfy KM, Al-Attas OS, Krishnaswamy S, Mohammed AK, Albagha OM, et al. Association between type 2 diabetes mellitus-related SNP variants and obesity traits in a Saudi population. Mol Biol Rep 2014; 41: 1731-1740.

75. Saadi H, Nagelkerke N, Carruthers SG, Benedict S, Abdulkhalek $S$, Reed R, et al. Association of TCF7L2 polymorphism with diabetes mellitus, metabolic syndrome, and markers of beta cell function and insulin resistance in a population-based sample of Emirati subjects. Diabetes Res Clin Pract 2008; 80: 392-398.

76. Osman W, Tay GK, Alsafar H. Multiple genetic variations confer risks for obesity and type 2 diabetes mellitus in arab descendants from UAE. Int J Obes (Lond) 2018; 42: 1345-1353.

77. O’Beirne S, Salit J, Rodriguez-Flores J, Staudt M, Khalil C, Fakhro K, et al. Type 2 diabetes risk allele loci in the Qatari population. PloS One 2016; 11: e0156834.

78. Al Hannan F, O’Farrell P, Morgan MP, Tighe O, Culligan KG. Associations between single-nucleotide polymorphisms of ADIPOQ, serum adiponectin and increased type 2 diabetes mellitus risk in Bahraini individuals. East Mediterr Health J 2016; 22: 611-618.

79. Al-Serri A, Ismael F, Al-Bustan S, Al-Rashdan I. Association of the insertion allele of the common ACE gene polymorphism with type 2 diabetes mellitus among Kuwaiti cardiovascular disease patients. J Renin Angiotensin Aldosterone Syst 2015; 16 : 910-916.

80. American Diabetes Association. Lifestyle Management: Standards of Medical Care in Diabetes-2018. Diabetes Care 2018; 41 (Suppl 1): S38-S50.

81. Luo L, Pang B, Chen J, Li Y, Xie X. Assessing the Impact of Lifestyle Interventions on Diabetes Prevention in China: A Modeling Approach. Int J Environ Res Public Health 2019; 16: 1677.

82. Wharton S, Pedersen SD, Lau DCW, Sharma AM. Weight Management in Diabetes. Can J Diabetes 2018; 42 Suppl 1: S124-S129.

83. Saboo B, Joshi S, Shah SN, Tiwaskar M, Vishwanathan V, Bhandari $S$, et al. Management of diabetes during fasting and feasting in India. J Assoc Physicians India 2019; 67: 70-77.

84. Veerman JL, Sacks G, Antonopoulos N, Martin J. The Impact of a Tax on Sugar-Sweetened Beverages on Health and Health Care Costs: A Modelling Study. PLoS One 2016; 11: e0151460.
85. American Diabetes Association. 2. Classification and Diagnosis of Diabetes: Standards of Medical Care in Diabetes-2020. Diabetes Care 2020; 43 (Suppl 1): S14-S31.

86. Sulaiman N, Mahmoud I, Hussein A, Elbadawi S, Abusnana S, Zimmet P, et al. Diabetes risk score in the United Arab Emirates: a screening tool for the early detection of type 2 diabetes mellitus. BMJ Open Diabetes Res Care 2018; 6: e000489.

87. Association AD. Improving care and promoting health in populations: Standards of Medical Care in Diabetes-2020. Diabetes Care 2020; 43 (Supplement 1): S7-S13.

88. Wan EYF, Fung CSC, Jiao FF, Yu EYT, Chin WY, Fong DYT, et al. Five-Year Effectiveness of the Multidisciplinary Risk Assessment and Management Programme-Diabetes Mellitus (RAMP-DM) on Diabetes-Related Complications and Health Service Uses-A Population-Based and Propensity-Matched Cohort Study. Diabetes Care 2018; 41: 49-59.

89. Pitchika A, Vehik K, Hummel S, Norris JM, Uusitalo UM, Yang J, et al. Associations of Maternal Diabetes During Pregnancy with Overweight in Offspring: Results from the Prospective TEDDY Study. Obesity (Silver Spring, Md) 2018; 26: 1457-1466.

90. Le Moullec N, Fianu A, Maillard O, Chazelle E, Naty N, Schneebeli C, et al. Sexual dimorphism in the association between gestational diabetes mellitus and overweight in offspring at 5-7 years: The OBEGEST cohort study. PLoS One 2018; 13: e0195531.

91. Abualhamael S, Mosli H, Baig M, Noor AM, Alshehri FM. Prevalence and Associated Risk Factors of Gestational Diabetes Mellitus at a University Hospital in Saudi Arabia. PakJ Med Sci 2019; 35: 325-329.

92. Groof Z, Garashi G, Husain H, Owayed S, AlBader S, Mouhsen $\mathrm{H}$, et al. Prevalence, risk factors, and fetomaternal outcomes of gestational diabetes mellitus in Kuwait: A cross-sectional study. J Diabetes Res 2019; 2019: 9136250.

93. Bogari NM. Genetic construction between polycystic ovarian syndrome and type 2 diabetes. Saudi J Biol Sci 2020; 27: 2539-2543.

94. Dargham SR, Shewehy AE, Dakroury Y, Kilpatrick ES, Atkin SL. Prediabetes and diabetes in a cohort of Qatari women screened for polycystic ovary syndrome. Sci Rep 2018; 8: 3619.

95. Lin PJ, Kent DM, Winn A, Cohen JT, Neumann PJ. Multiple chronic conditions in type 2 diabetes mellitus: prevalence and consequences. Am J Manag Care 2015; 21: e23-e34.

96. Iglay K, Hannachi H, Joseph Howie P, Xu J, Li X, Engel SS, et al. Prevalence and co-prevalence of comorbidities among patients with type 2 diabetes mellitus. Curr Med Res Opin 2016; 32: 1243-1252. 